\title{
LA PRIMERA PALABRA, O LA ESENCIA DEL LENGUAJE COMO AMPARO
}

\author{
Josep M. Esquirol \\ Universidad de Barcelona
}

\section{Resumen}

En este artículo se defiende que el sentido esencial del habla, antes que en la enunciación del mundo y antes también que en el intercambio informativo, reside en su función de amparo y de acogida. Para la argumentación se atiende tanto a algunos giros del lenguaje coloquial como a reflexiones filosóficas sobre el lenguaje como la de Emmanuel Lévinas. Palabras clave: lenguaje, amparo, condición humana, Lévinas.

\section{Abstract}

In this paper it is upheld that the essential sense of speech lies in its function of shelter and taking in, better than in the enunciation of the world or the exchange of information. As to the arguments, both some turns of colloquial language and some philosophical reflections on the language, such as that of Emmanuel Lévinas are stated.

Keywords: language, shelter, human condition, Lévinas.

Debemos a Lévinas, entre otras cosas, el poder usar de nuevo ciertas palabras para pensar. "Adiós” es una de ellas. En la oración fúnebre pronunciada durante su sepelio por Jacques Derrida ${ }^{1}$, reconoce éste que "adiós" es una palabra que Lévinas le enseñó a pronunciar de otra manera. De otra manera respecto al automatismo de la despedida habitual, sin duda. Pero, probablemente, no tan lejos de su primera significación. "Adiós", "Ve con

Recibido: 18/05/2011. Aceptado: 20/07/2011.

${ }^{1}$ Derrida, J., Adiós a Emmanel Lévinas. Palabra de acogida, Madrid, Trotta, 1998. 
Dios" o "Dios te guarde", indican lo mismo: protección y amparo. De ahí que sean literalmente "saludos" (de encuentro o de despedida), es decir, palabras que desean salud, salvación. En tiempos de ausencia de Dios, nada extraño es, pues, que el "adiós" se sustituya por el "cuídate". Aunque, quizás, antes de "cuídate" lo más lógico hubiera sido decir "que te cuiden". $¿$ ¿Se han ausentado los otros junto con Dios, o tal vez Dios era ya nombre de los otros, y el cuidar de los otros era ya el cuidar de Dios?

En este escrito se ensaya una tesis sobre la esencia del lenguaje; tesis bastante afín a la ya anticipada por Lévinas en Totalidad e infinito cuando afirma que la esencia del lenguaje es amistad y hospitalidad ${ }^{2}$.

\section{El giro lingüístico}

Para situar las cosas, y aunque sea sucintamente, conviene poner en relación esta búsqueda de la esencia del lenguaje con el "giro lingüístico" de la filosofía contemporánea. Sabemos que este giro puede ser expresado en forma de pregunta transcendental: ¿Cómo es posible el lenguaje? y sabemos que esta pregunta ha tenido dos grandes grupos de respuestas: las primeras alrededor del primer Wittgenstein y de Russell, determinando una estructura lógica del lenguaje y suponiendo que la función esencial del lenguaje es descriptiva. El lenguaje trataría, principalmente, de decir el mundo, en el sentido de enunciarlo y de establecer cómo son las cosas y los hechos. De ahí que lo importante sea la proposición (unidad lingüística que dice como es un hecho) y su correspondencia con la realidad (verdad o falsedad). En este tipo de planteamiento, las actitudes proposicionales se consideran como algo derivado de, o construido sobre, la proposición elemental. Si "llueve" es la proposición que dice el mundo; "quiero que llueva" es la actitud proposicional. (Pero, ¿̇i la perspectiva no fuese la lógica sino la existencial, no sería primero la actitud?). La teoría de la proposición enlaza con la teoría de los nombres: los objetos se nombran del mismo modo que los hechos se describen. Así, la primera época de la filosofía del lenguaje se caracterizó por la búsqueda de las condiciones lógicas y semánticas de un lenguaje perfecto, es decir, de un lenguaje que describiera correctamente los estados de las cosas del mundo. Pero esta intención (la del lenguaje perfecto) es la que se dejó de lado en el segundo grupo de respuestas a la citada pregunta (“¿cómo es posible el lenguaje?”), encabezado por el propio Wittgenstein

${ }^{2}$ Lévinas, E., Totalidad e infinito, Salamanca, Sígueme, 1977, p. 309. 
(no, pues, el del Tractatus sino ya el de las Investigaciones filosóficas). En tal momento el presupuesto no fue que la lógica iba a ilustrarnos sobre la estructura del lenguaje y la realidad, sino que el lenguaje ordinario era más rico que la lógica y que, por tanto, debía tener preferencia en el estudio filosófico. El "segundo" Wittgenstein cree que no hay algo así como "la esencia" (única) del lenguaje en general, sino que lo que hay es una gran diversidad de fenómenos lingüísticos, de juegos lingüísticos, que pueden agruparse según el aire de familia que compartan. El objetivo no será, entonces, elaborar una clasificación de las proposiciones según su estructura y según el significado de las palabras, sino la descripción de los usos lingüísticos. Dicho de otro modo: la semántica cede el protagonismo a la pragmática. El relevo en este tipo de planteamiento fue decididamente asumido por Austin en su obra de título más que elocuente: ¿Cómo hacer cosas con palabras?33. Así la reflexión filosófica sobre el lenguaje pasaba a ser una parte - y muy importante- de la reflexión sobre la acción.

\section{Sobre la pista}

Tras este viraje, ¿cabe formular la pregunta por la esencia del lenguaje? Responder afirmativamente significaría buscar la acción lingüística primordial. Esto es, por ejemplo, lo que en cierto modo ha hecho Habermas al poner lo que él llama "acción comunicativa" (kommunikatives Handeln) no sólo como el eje de su teoría ética y filosófica sino también como la especificidad de lo humano. La función comunicativa del lenguaje sería la función primordial del lenguaje, distinta de la acción instrumental y de la estratégi$\mathrm{ca}^{4} \mathrm{y}$, evidentemente, contrapuesta al engaño, al dominio y a la violencia.

Junto con la importancia filosófica dada a la idea de comunicación, tenemos también, y por razones más que obvias, la concepción del lenguaje como información. Que este término se haya convertido en expresión epocal ("era de la información") es ya bastante revelador. La fuerza de este modo de ver las cosas procede de la suma de dos fuentes: por una parte, la del dominio actual de las tecnologías informáticas, con la creación de redes globales de flujos de información y, por otra parte, la de las teorías biologicistas, que definen todo organismo (el hombre incluido, por supuesto) como unidad-sistema capaz de procesar información.

\footnotetext{
${ }^{3}$ Austin, J. L., Cómo hacer cosas con palabras: Palabras y acciones, Barcelona, Paidós, 1982.

${ }^{4}$ Habermas, J., Teoría de la acción comunicativa, 2 vols., Madrid, Taurus, 1987.
} 
Los términos "comunicación" e "información" son poco precisos y, en especial, el primero. Sin embargo, no cuesta mucho advertir que en la idea de comunicación (teoría habermasiana incluida) sigue siendo central la proposición que dice el mundo. De modo que, a fin de cuentas, se sigue interpretando el lenguaje sobre todo como discurso y como procesamiento e intercambio de información. Aunque, según como se mire, esto sólo es una novedad por la especificidad que adquiere hoy el tema de la información, pues ya había sido una de las maneras recurrentes de interpretar la vieja definición de hombre como animal dotado de logos: ser con capacidad discursiva, que puede nombrar las cosas, decir el mundo e intercambiar visiones de mundo. Así pues, aun con la inflexión pragmática en la filosofía del lenguaje, el registro enunciativo-informativo sigue siendo el primer analogado.

Sin embargo, esta persistencia no quita -más bien al contrario- la oportunidad de volver a cuestionar: ¿Hay algún tipo de habla (gesto radical o archigesto) que sea más grave que los demás y en relación con el cual los demás, por lo menos en parte, tienen que ver? ¿Un gesto diferente al del intercambio de información y diferente, también, del discursivo y enunciativo del mundo? ¿Podrían ser el amparo y el ruego las dos modalidades de tal archigesto? Entonces, en la palabra de amparo y de plegaria se encontraría el camino que conduce a la esencia del habla. Aunque el camino sería ya el sentido mismo, lugar de tránsito pero también posada. Y no se trataría de una respuesta doble: la plegaria (el ruego o la súplica) es la continuación del amparo (o de la acogida) $)^{5}$

He de hacer constar que esta tesis (o esta hipótesis) además de vecina de Lévinas lo es de lo que, discutiendo con Habermas, ha apuntado también J.B. Metz situando lo esencial en el clamor ${ }^{6}$.

No se trata de una tesis piadosa, en el sentido de buscada a partir de una posición piadosa; es filosófica, es decir, pretende comprender un poco más. Aunque, ciertamente, la propia tesis sí tiene que ver con la piedad, puesto que alude directamente al cuidado del otro. Amparo o acogida se refieren,

\footnotetext{
${ }^{5}$ Por razones que se advertirán en el texto, hemos optado por hablar más de amparo aunque también hubiéramos podido escoger "acogida" o "guarda". Guardar quiere decir mirar con atención y quiere decir también tener cura. Guardar es prestar atención, cuidar, respetar, vigilar para que no suceda un daño. Guardar y resguardar expresan nuestro modo fundamental de ser. Guardamos para proteger, para amparar, para preservar del mal y de la desaparición. Como cuando alguien guarda un recuerdo. No por casualidad, la memoria es uno de los modos privilegiados del cuidar. "Quita la memoria y desaparecerá el amor", escribía Rousseau. Guarda y resguarda la palabra del recuerdo (la palabra cordial) y guarda y resguarda la palabra de la promesa.

${ }^{6}$ Cfr. Metz, Memoria passionis, Santander, Sal Terrae, 2007, p. 105.
} 
justamente, a solicitud y cuidado por el otro; a lo que, si fuéramos capaces de restarle el movimiento inercial que suele acompañarla, emergería de la pregunta: “¿Cómo estás?”. Una pregunta nada banal, a pesar de que tantas veces se use tan vacía. Que todavía hoy en los encuentros vaya por delante el “¿cómo estás?" es muy significativo. La profundidad del "¿cómo estás?" es la misma que la del "adiós" —ambas encubiertas por los pliegues de la costumbre, de la indiferencia o del olvido.

Para argumentar a favor de esta hipótesis no voy a descartar las otras respuestas y menos aún las más clásicas. De Heidegger cabe aprender a buscar lo verdadero (lo más profundo) a través de lo correcto ${ }^{7}$. En vez de descartar, pues, hay que saber escuchar el eco de lo esencial que se da, por ejemplo, en el canto o incluso en la palabra que comunica y en la palabra que informa. Y considerar en las antípodas no tanto el error como la demagogia o la violencia.

\section{Cantar para alejar el miedo}

"Quien canta, su mal espanta" —reza la sabiduría popular. Quien canta dice afectivamente el mundo, y la vida, y a sí mismo. Quien canta, se canta. Su voz no sólo resuena a su alrededor, sino también en su propio cuerpo y en su alma. El canto expresa un conocimiento esencial de la situación; pero no un conocimiento preciso desde el punto de vista "objetivo", sino relevante en su significación derivada de una particular conexión con el mundo. Esto es: su riqueza no reside en la elaboración argumentativa o discursiva, sino en la tonalidad y la variación cordial que sintoniza con la frecuencia de las cosas; tonalidad que traduce la visibilidad y la propia sonoridad de las cosas. Esta es la razón que explica por qué la mejor poesía (que de ser buena es también canto) es la que sabe conectar de nuevo; es la de aquellas palabras en cuya tonalidad se renueva la maravilla de la sinapsis. La pérdida de mundo va siempre de la mano con la perdida de la musicalidad ${ }^{8}$.

Ahora bien, la poesía y el canto piden al otro y son ya inicio o final de conversación. Un diálogo auténtico es como un canto a dos voces. Nos decimos el mundo, y nos decimos a nosotros mismos. Por eso el diálogo -el pensar juntos- es mucho más que un simple intercambio; es contacto y compañía que dice, celebra y al mismo tiempo se protege del mundo.

${ }^{7}$ Cfr. el inicio de "La pregunta por la técnica", en Conferencias y artículos, Barcelona, Serbal, 1994, p. 11.

${ }^{8}$ Cfr. Otto, Walter F., Las Musas y el origen divino del canto y del habla, Madrid, Siruela, 2005 . 
El poema de un humilde poeta rural, recitado por una mujer con la fortaleza de la experiencia, no tiene parangón. ¿Por qué ninguna sutileza intelectual puede ni siquiera aproximársele? Pues porque poeta y mujer saben, sin titulaciones, conectar con el tono de las cosas mismas, de las situaciones. Una canción puede levantarse y llegar muy arriba sin dejar de tener los pies en el suelo, por la perfecta sintonía que pueda alcanzar con aquello que canta. Esto, la mujer que recita lo tiene gracias a la experiencia de la maternidad y del cuidado. Su voz cose el azul del cielo con la tierra nodriza. La madre canta para que el niño no tenga miedo. Canto materno que, de hecho, es plegaria, tal como podrían sugerir los hermosos versos de Giovanni Pascoli de su poema "Nevicata":

"passano bimbi: un balbettìo di pianto;

passa una madre: passa una preghiera."

De mayor, el niño también va a cantar para no sentir miedo. Deleuze tiene, en este sentido, unas páginas muy interesantes comentando el ritornello, la cancioncilla con la que el niño, preso por el miedo, intenta calmarse y resguardarse: "Un niño en la oscuridad, presa del miedo, se tranquiliza canturreando. Camina, camina y se para de acuerdo con su canción. Perdido, se cobija como puede o se orienta a duras penas con su cancioncilla. Esa cancioncilla es como el esbozo de un centro estable y tranquilo, estabilizante y tranquilizante, en el seno del caos."

\section{De la información al gesto formador}

A diferencia del lenguaje poético y del canto, que mantienen vecindad, aquí la lejanía con respecto a lo esencial es muy grande. Hoy se habla del "estar informados" en el sentido de saber enciclopédico sobre las cosas y en el sentido de "tener noticia" de lo que pasa en el mundo. La información parece como el discurso científico popular: sumatorio continuado de "conocimientos" y de noticias; como si el mundo fuese un muestrario de productos y de hechos cada uno de ellos con su posible etiqueta. La información da cuenta de un mundo fijado objetivamente. A partir, sobre todo, de Husserl y de Heidegger podemos entender la razón por la que el lenguaje de la información es propio y característico de la era de la ciencia y la tecnología. Lenguaje "objetivo" que da cuenta de un mundo igualmente "objetivo". El gran presupuesto de la ciencia moderna consiste en creer que todo

${ }^{9}$ Deleuze, G. y Guattari, F., Mil Mesetas, trad. J. Vázquez Pérez, Valencia, Pre-textos, 1997, p. 318. 
es determinable (lo que en modo alguno es incompatible con el principio de indeterminación de la mecánica cuántica).

No se nos pasa por alto que a la idea de determinación acompaña la de poder: saber cómo son las cosas permite ser eficaz en su manipulación. Información significa, en cierto sentido, control, dominio - “información es poder", reza el eslogan. Paradoja: si bien, por un lado el lenguaje fija y asegura las cosas, por otro lado la enorme masa de información se reproduce y desaparece sin cesar y la información va siendo sustituida fluidamente por más y nueva información. "Todo es información” — se dice- y el mundo se llena de cables y se atraviesa de ondas. En este nuevo medio navegamos o somos náufragos, o ambas cosas al mismo tiempo.

Si bien - como ya se ha dicho- la filosofía ha dejado de lado la búsqueda del lenguaje perfecto, ahora parece que el lenguaje de la información juntamente con el cientificista se autoconstituyen como el modelo paradigmático de lenguaje porque son los que explican el mundo. He aquí la incongruencia: no dominamos el mundo por medio de la lengua materna, $\mathrm{y}$-mira por dónde-creemos hacerlo mediante el lenguaje informacional. ¿Cómo puede ser esto? Con el lenguaje coloquial nos orientamos, con el informativo creemos dominar. ¿Por qué uno es más modesto que otro? ¿Qué manera de relacionarnos con el mundo se da mediante cada uno de ellos? "Disponemos" de información. No disponemos del sentido de las cosas. El juicio y el sentido común exigen maduración; y no es lo mismo disponer de información que tener juicio. Esta enfermedad ha llegado incluso a las llamadas ciencias humanas y sociales, a menudo con un simulacro de lenguaje, que no es ni una cosa ni otra: ni tiene la sedimentación y la flexibilidad del lenguaje natural ni el rigor del lenguaje formal o de las ciencias físicas ya consolidadas. No hay maduración del juicio y el pretendido dominio de su objeto con un lenguaje preciso y especializado es una ilusión (empezando porque ya ni siquiera es claro que haya "objeto").

Pero he aquí que la información contiene la idea de formación y ésta la necesidad de la figura, la consistencia, la forma... De modo que, incluso hoy, en un contexto que juega más bien en contra, por dispersión, ya sería mucho saber poner de nuevo la información en el camino de la formación. Cabría, así, escuchar aún el eco de lo esencial. Ahora bien, no es la acumulación, sino lo poco pero valioso lo que puede formar. Al profesor que enseña a los alumnos o a los padres que educan a los hijos, les ha de preocupar, sobre todo, el gesto, la palabra, la mirada que forma. De otro modo, es que ya hemos tomado una dirección equivocada; extravío más que secular, tal como se pone de manifiesto en esta inestimable anécdota de unos de los padres del desierto: Se cuenta que el abate Teodoro se negó a hablar con un 
hermano que había ido a verle, y cuando un compañero se lo recriminó, le respondió: "No quise hablarle porque se daba mucha importancia y se gloriaba de emplear palabras raras". Cuesta poco imaginarse la escena, puesto que hoy día vemos muchas similares, una tras otra.

\section{El deterioro del lenguaje: San Benito y Foucault}

El deterioro del lenguaje y su degeneración tienen modalidades distintas. En una dirección significativa de esta degeneración se encuentran la verborrea y el murmurio. La verborrea es la locuacidad excesiva que, como tal, tiene también poca sustancia. En cierto modo, la sociedad actual ha pasado de la propaganda a la verborrea (manteniendo la primera). Así como hay una propaganda explícita y otra más sutil y solapada, también hay una verborrea barullera y escandalosa y otra que se disfraza de ciencia y seriedad.

El murmullo consiste en hablar en voz baja, especialmente para quejarse de alguna cosa o de alguien. Rumor y ruido de fondo. Realmente significativas son, en este tema, las advertencias de San Benito en su regla. Resulta que una de las conductas que más le inquietaban era la del murmurar. Sale varias veces y de forma muy poco forzada: "No ser murmurador" (IV); "Sobre todo que no se manifieste el mal de la murmuración, por ningún motivo, sea el que sea, ni con la más mínima palabra o señal” (XXXIV); y se nos dibuja una sonrisa en los labios con este otro artículo en el que se relaciona al vino con el del murmurio: "Aunque leemos que el vino en modo alguno es propio de los monjes, como en nuestros tiempos no se los puede persuadir de ello, convengamos al menos en no beber hasta la saciedad sino moderadamente, porque «el vino hace apostatar a los sabios». Pero donde las condiciones del lugar no permiten conseguir la cantidad que dijimos, sino mucho menos, o nada absolutamente, bendigan a Dios los que allí viven, y no murmuren. Ante todo les advertimos de esto, de que no murmuren" (XL). Hoy, el murmullo no proviene de la falta de vino y más que de la escasez procede del exceso de demasiadas cosas. A diferencia de la protesta diáfana, el murmullo medio se esconde; su timidez forma parte de su bajeza. No posee el coraje de la confrontación y está en el otro extremo de la alegría y del agradecimiento; por eso es enfermizo. Egocéntrico por definición, quien murmura ignora la propia finitud e incuba un sentimiento de insatisfacción y de mezquindad respecto a todo lo que le envuelve. Y por eso lleva a enfermar, cuerpo y alma, por el amargor de esta insatisfacción contenida. No tiene nada que ver ni con la compasión ni con la denuncia 
de la injusticia. ¿Qué papel juega en él el lenguaje? Pues se deteriora hasta el punto de que las palabras no tienen ya ningún sentido. Casi sólo cuenta ya la monotonía de los fonemas indiferenciados. El tono lo dice todo. Si de la murmuración se conservase sólo el tono, sin palabras, no se perdería nada y, en su contexto, la acción haría el mismo efecto. Por eso el murmullo es un ejemplo inmejorable de palabra vacía, de traición a la palabra, de sucedáneo. La palabra tiene poder sobre la vida y sobre la muerte, pero el murmullo sólo tiene el poder de la carcoma que agujerea su propio mundo. No proyecta nada ni es capaz de nada, sólo consume.

Si San Benito avisa de los indeseables efectos del murmullo, Foucault hace en sus últimos escritos una defensa muy significativa de la franque$z a^{10}$. Se trata, en concreto, del concepto griego de parresía, que Foucault entiende muy vinculado a toda la temática clásica del cuidado del alma (epiméleia heautoû) y de la ascesis en las escuelas filosóficas de la antigüedad. La parresía es franqueza, es ponerlo todo en el decir; es sinceridad: ser enteramente uno mismo al hablar. Etimológicamente, pues, parresía significa decirlo todo (no en el sentido del conjunto, sino en el de decir lo que uno piensa). Contrasta con la demagogia y con la retórica, que sólo persiguen persuadir. No pretende sobresalir, sino decir lo que uno cree. Mientras la retórica recurre al discurso largo y embellecido, la parresía recurre al diálogo y al tú a tú. A menudo ser franco y sincero requiere coraje. También a menudo es más fácil disimular. El parresiastés está siempre en situación de una connivente inferioridad respecto a aquel al que dirige su habla. Como Sócrates cuando se dirige a la asamblea. La parresía es condición de una relación verdadera con el otro (sin retórica ni adulación). En el cuidado de sí resulta de capital importancia la palabra. ¿Y podría ser de otro modo que palabra sincera? Quien habla con franqueza habla con libertad, por eso la traducción de parresía al latín es libertas. Hay, sin duda, una conexión entre la parresía de que habla Foucault, la austeridad de palabras de los padres del desierto, y la precaución de san Benito respecto al murmullo.

Murmullo y demagogia son el veneno de toda comunidad. Tenemos de ambos cantidades ingentes que lo llenan todo, desde la vida cotidiana, pasando por los mass media, hasta la política, e incluso la cultura y la academia. Opulenta miseria, hablar vacío, ininterrumpido, que nada tiene y nada da.

${ }^{10}$ Cfr. Foucault, M., Historia de la sexualidad 3. La inquietud de sí, México, Siglo XXI; El gobierno de si y de los otros, México, FCE; Discurso y verdad en la antigua Grecia, Barcelona, Paidós, 2004. 
Pero aún más allá, en radical oposición a lo esencial, están el engaño, el insulto y la violencia. La violencia es muda ${ }^{11}$, aunque pueda ir acompañada de palabras; es del orden de la indistancia y de la indiferencia. Peor que el error es el engaño, y peor que el engaño, el insulto; por eso, el insulto está mucho más alejado de lo esencial que el error; por eso, la esencia del lenguaje tiene más que ver con la sinceridad que con la verdad. La mala lengua, como el filo de la navaja; "lengua viperina", venenosa como la de la víbora. La mala lengua hiere y mata a los demás, pero también a uno mismo. He aquí pues, en rápido repaso, formas y grados de deterioro del lenguaje y de traición de la primera palabra.

\section{El silencio para recuperar la palabra}

El silencio, en cambio, no es mudo sino, con frecuencia, muy significativo y elocuente. Lo contrario de la palabra no es el silencio, sino - como acabo de decir- la violencia. Fenómeno equívoco, porque también la muerte es silencio y, después de las bombas, el silencio reina en los campos de batalla. Hay, pues, distintas modalidades de silencio. Una de ellas es, sin duda, la mejor cura contra las enfermedades degenerativas de la palabra. Alejamiento de lo que merece ser apartado y acceso a lo esencial. ¿Por qué es el silencio el lugar más adecuado para la oración y la plegaria? ¿Por qué el silencio es la matriz fecunda de la palabra? ¿Tal vez porque es condición de la escucha y de la proximidad? Los ríos más grandes son los más silenciosos. El silencio es, efectivamente, un ejercicio de salida y de acceso. De salida de lo que tapa, y de acceso a la serenidad y la calma. De salida del apretujamiento, de la aceleración y del ruido ambiental (al hilo musical de la década de los setenta y ochenta lo ha sucedido la información ininterrumpida durante todo el día y todos los días del año). "En todas las cimas hay calma", decía Goethe, y toda calma es ya una cima — podríamos añadir-; en ella, ahora sí, se escucha el eco de lo esencial. Hay un pasaje del libro de Job que siempre me ha llamado mucho la atención. Cuando los amigos de Job se enteran de las desgracias que le han pasado, van a verle, y dice la narración: "Luego se sentaron en el suelo junto a él, durante siete días y siete noches. Y ninguno le dijo una palabra, porque veían que el dolor era muy grande.” (Job, 2, 13). Este silencio que acompaña y que consuela es la primera palabra. Y sin embargo este pasaje queda después sobrepasado

\footnotetext{
${ }^{11}$ Cfr. Weil, E., Logique de la philosophie, Paris, Vrin, 1950, pp. 56-57.
} 
por los inacabables discursos de los tres amigos. Decididamente, hablan demasiado; mejor se lo podrían haber ahorrado, y el centro, en vez de ese discursear, lo constituyera aquel silencio ${ }^{12}$.

Podemos preguntarnos: ¿Cómo sentimos el silencio? Y ¿cuál es este sentir en el que el silencio nos sitúa y que nos permite sentir el propio silencio?

\section{El tacto del contacto: Lévinas}

Para Lévinas - con el que la deuda por mi contraída es ya impagable-, el "lenguaje original", o el logos del prólogo (pre-logos), es proximidad y contacto. Ahora bien, mientras Lévinas interpreta este contacto como responsabilidad y sustitución (conceptos que requieren mucha atención y el acceso a los cuales lo es al núcleo de su filosofía), aquí — como ya se ha dicho al empezar- relacionamos la proximidad y el contacto con el amparo y la plegaria.

Según Lévinas, el Decir y la caricia son modalidades del acercamiento. Ambos son expresión de una responsabilidad que sobrepasa cualquier relación de reciprocidad. Que el otro es hermano significa que estoy ligado a él por una exigencia, por una demanda. Y el insomnio (definición de nuestro psiquismo) es la condición en la que me instaura. ¿En qué cosiste la diferencia entre lo Dicho y el Decir? Lo Dicho es el lenguaje destinado a enunciar lo que es, a representar el mundo, a sistematizarlo y, así, a comprenderlo. El Decir se corresponde con el "acontecimiento de la proximidad $^{13}$; es el "lenguaje original". El Decir significa una responsabilidad sin frases ni palabras; es anterior al lenguaje verbal: "prólogo de las lenguas". Lo Dicho es el lenguaje de la tematización; se trata de enfocar las cosas y, de algún modo, fijarlas como tales, constituirlas, darles sentido —como diría Husserl. En este registro, la significación del lenguaje procedería de la primera identificación de una cosa en tanto que tal cosa: el martillo en tanto que martillo. La base de la tematización y del juicio está en la identificación, lo que permite decir a Lévinas que se da una especie de prioridad de lo universal (la idealidad) respecto a lo singular. Y todavía en este registro, la comunicación resulta subsidiaria y consiste básicamente en la transmisión

${ }^{12}$ La misma valoración la encontramos en: Neher, A., El exilio de la palabra. Del silencio bíblico al silencio de Auschwitz, Barcelona, Riopiedras, 1997, pp. 34-35.

${ }^{13}$ Las citas de este apartado lo son de un texto de Lévinas titulado precisamente: "Langage et proximité" contenido en: En découvrant l'existence avec Husserl et Heidegger, París, Vrin, 1982, p. 218 y ss. Citaremos según la traducción castellana: Descubriendo la existencia con Husserl y Heidegger, Madrid, Síntesis, 2005, p. 309 y ss. 
de mensajes. En contraste con ello, la tesis de Lévinas es que "cualquiera que sea el mensaje transmitido por el discurso, el hablar es contacto" ${ }^{14}$. Lo cual presupone que el discurso mismo es deudor de una singularidad que no está tematizada por el discurso, sino aproximada. Y "la proximidad es por ella misma significación" ${ }^{15}$. Esta significación, previa a la tematización (a la husserliana donación intencional de sentido) es, según Lévinas, el "lenguaje original", fundamento del otro. "Proximidad" que puede llamarse, también, "relación ética" (o todavía mejor: relación ética que debe entenderse, sobre todo, como proximidad). A pié de página Lévinas la define así: "Calificamos como ética una relación entre términos donde uno y otro no están unidos ni por una síntesis del entendimiento ni por la relación de sujeto a objeto y donde, sin embargo, uno pesa, importa o es significante al otro, donde están unidos por una intriga que el saber no sería capaz ni de agotar ni de desenredar." 16

La proximidad no tiene nada que ver con la amplificación de la lupa. En Lévinas, la proximidad es la dimensión de la sensibilidad, que, a su vez, tiene en el tacto (y no en la vista) su expresión más emblemática: "Pero lo sensible debe interpretarse primordialmente como tacto." ${ }^{17}$ El gusto de las cosas, y el tacto de la piel. En general, hemos otorgado demasiado peso y protagonismo a la vista: mirada desde la distancia, visión de conjunto, contemplación... Sin embargo, la propia vista podría interpretarse en términos de tacto: "Se ve y se oye como se toca." ${ }^{18}$ Lo que, en otra parte, he llamado "mirada atenta" trata de entender la mirada en cuanto aproximación con tacto ${ }^{19}$.

“Aproximar al Prójimo (Autrui) todavía es proseguir lo que ya está presente, buscar todavía lo que se ha encontrado, no poder ser indiferente hacia el próximo (le prochain)." ${ }^{20}$ Especialmente significativa, "la caricia es la unidad de la aproximación y la proximidad". Sin embargo, la proximidad, que es presencia del rostro, de la piel humana, es también ausencia. En la proximidad está la traza del infinito (y mejor decir traza que no huella: huella es la señal dejada en el suelo por el hombre o el animal; la traza es simplemente la señal dejada por alguien o alguna cosa al pasar).

\footnotetext{
${ }^{14}$ Ibid., p. 319.

${ }^{15}$ Ibid., p. 320.

${ }^{16}$ Ibid., p. 320.

${ }^{17}$ Ibid., p. 322.

${ }^{18}$ Ibid., p. 323.

${ }^{19}$ Cfr. Esquirol, J. M., El respeto o la mirada atenta, Barcelona, Gedisa, 2010 (3 ed.).

${ }^{20}$ Lévinas, op. cit., p. 326.
} 
El Decir es ajeno al poder; está en el centro de la anarquía. De hecho, el Decir es la expresión de la anarquía, de una situación donde la asimetría nada tiene que ver con el dominio, sino con la acogida y el recibimiento. Asimetría de la responsabilidad, y no asimetría del dominio. Mientras la retórica de la persuasión está al servicio del poder, el Decir anárquico no se preocupa por asegurar los hitos discursivos: no insiste en el: "es que yo he dicho que..."; lo Dicho queda desplazado hacia un segundo plano.

Finalmente y resumiendo, comparto con Lévinas que "quizá hemos cesado de asombrarnos por todas las implicaciones de la proximidad y el acercamiento." ${ }^{21} \mathrm{Y}$ creo que es por eso por lo que andamos confundidos con respecto a la esencia del habla y tenemos desviada la atención hacia el lugar equivocado. Encaminarnos de nuevo en la buena dirección nos permitiría, como a Lévinas, valorar la significación del lenguaje cotidiano: “en el lenguaje cotidiano nos aproximamos al prójimo en lugar de olvidarlo en el «entusiasmo» de la elocuencia." 22 Esta es la función, en efecto, de la aparente conversación intrascendente: hablar del tiempo, del fútbol o de lo mal que anda el mundo es una forma de aproximarse. El tema es secundario, y lo que importa es responder de la relación. A veces, si es con alguien desconocido, precisamente de lo que se trata es de "romper el hielo" y responder al primer contacto que es ya una primera demanda. Casi no sería ya necesario volver a recordar que la degeneración es siempre fácil, y que también la verborrea y la banalidad más indistante invaden la cotidianidad.

Lenguaje como no-indiferencia ante el otro; no-indiferencia vacunada contra las invitaciones a la elocuencia; no-indiferencia ajena al saber y al poder; no-indiferencia que procede de la proximidad y que, a la vez, significa una trascendencia.

\section{Sobre la situación humana y el lenguaje: ¿el océano o el desierto?}

Evidentemente, la comprensión de la esencia del habla no puede ser ajena a la forma de describir - $\mathrm{y}$, por tanto, de comprender- la situación humana. Aunque no cabe desarrollar aquí y en extenso este punto, sí es oportuno aludir brevemente a dos grandes metáforas rivales entre sí: la del desierto y la del océano. Según ya puede sospecharse, la palabra como amparo sólo tiene sentido en el desierto, no en el océano.

${ }^{21}$ Lévinas, De otro modo que ser, o más allá de la esencia, Salamanca, Sígueme, 1987, p. 48.

${ }^{22}$ Lévinas, Fuera de sujeto, Madrid, Caparrós, 1997, p. 156. 
Desiertos no sólo son los de arena; los hay también de cemento. Pero, en cualquier caso, el desierto nunca es el océano; no supone inmersión. El perfil humano, alargado, es como una grapa que une cielo y tierra; una línea vertical (una "i") sobre la magna extensión de tierra y bajo el cielo implacable y a la vez protector. El desierto no es el océano. El caminante hace ruta en él orientándose por el curso del sol de levante a poniente. Los elementos, con su inmensidad y dureza, acompañan sin embargo el camino del mortal. Ni tan siquiera el perderse en el desierto es un disolverse: es muerte.

Pero somos con los demás. Por así decirlo, es en el desierto donde el otro se me aparece como tal y donde recibe de mí acogida. Mi voluntad, implicada en este gesto hacia el otro, es voluntad en el desierto; es voluntad precisamente debida al desierto. La tierra es redonda, pero el suelo es plano y sobre la explanada caminamos juntos hasta agotar nuestras fuerzas. No es exactamente un muro al final, sino la propia tierra la que nos reclama y la poca fuerza que aún pueda quedarnos para mantenernos de pie acaba por ceder. No es el muro, pues, sino la gravedad de la horizontal.

Sobre un plano, caminan los mortales hasta el desánimo de los finales presentidos pero con la ayuda de la fuerza vital de los que están cerca; se protegen del frío del norte y de la dureza soterrada; piden cobijo y suplican palabra de acogida. No nos elevamos por encima de los tejados de las casas hacia el éter del cielo, ni nos hundimos en la densa masa de la tierra, sino que existimos sobre un plano, sobre una llanura. Esta situación determina el gesto y el pensamiento. Puede uno soñar, sí. Y evadirse. E imaginarse subiendo hacia lo alto, como los cometas o los globos de los niños. Pero hay que retornar siempre a esa llanura, a ese plano de la existencia.

El desierto ilustra la precariedad de la condición humana. Y no por casualidad "plegaria" tiene la misma raíz que "precario". La precariedad da sentido al amparo, el cual, sin embargo, no cabe en el océano; lo que en éste sí corresponde son la inmersión y la disolución. En el desierto hay acogida y muerte. En el océano no hay palabras o, si las hay, son las pertenecientes al discurso de la totalidad: letra mayúscula, palabra redonda y discurso circular. En el desierto, la palabra es una tienda. El Logos universal (divino) es del océano, y la plegaria es del desierto. Una larga línea de pensamiento ha identificado el Verbo, el Logos y la Razón universal y divina. La esencia del lenguaje humano no tiene mucho que ver con esto.

La religión es la experiencia del desierto (desiertos de arena, desiertos urbanos), no del océano. Tiene razón Freud cuando dice que el origen de la religiosidad no es el sentimiento oceánico sino la experiencia del 
desamparo ${ }^{23}$. Se le puede discutir, y mucho, que sea ésta una experiencia sobre todo infantil, así como que de esta experiencia se pueda pasar tan fácilmente a la tesis de la ilusión.

\section{El archigesto}

A aminorar la sorpresa que quizá provoque el poner la esencia del habla no en la comunicación-información sino en el amparo, tal vez ayude el darnos cuenta de cómo algunas palabras primordiales remiten a gestos originarios. Así, por ejemplo, el "no" no es el "no" de la negación ("la mesa no es redonda"), sino el "no" frente al mal y al sufrimiento; el "no" cual rechazo y barrera respecto a lo que se presenta como dañino y amenazador; así cuando se ponen las manos abiertas delante del cuerpo como queriendo evitar la irrupción del choque. De este "no" a la plegaria hay muy poco trecho; al no poderse evitar lo inevitable, el lenguaje se convierte en súplica y también en exclamación. El "sí", en cambio, se dibuja en la cara distendida y en la brillantez de los ojos; lo que también se expresa, por ejemplo, con el saludo franciscano: "Paz y bien". "Paz y bien" no son conceptos abstractos, sino la expresión que alude a lo mismo que toda palabra materna — susurro amoroso - con la que se acaricia y abriga; a toda palabra silente y ubicua del amigo, también acogedora, y a la palabra del maestro: ¿cómo se podría enseñar sin acogida?

La palabra no es la casa del ser, sino la casa del hombre. Protege, arropa y reconforta. La palabra hace las veces de abrigo y el texto es como el tejido; si es bueno protege del frío.

“¿Cómo estás?”, “¿cómo te encuentras?”, “me alegro de verte”, “cuídate", "adiós"... son expresiones de cuidado que conectan con lo esencial. Al prestarles atención, ¿puede uno, según decíamos a propósito de Lévinas, no maravillarse de su sentido? “¿Estás bien?” con franca solicitud es ya cuidar del otro. Literalmente una pregunta, pero, en realidad, tacto e imposición de manos. La mano que acaricia al niño nota su cuerpo y su pulso, pero al mismo tiempo le transmite calor y sosiego. Casi está de más recordar que la expresión “¿cómo estás?” puede ser perfectamente silenciosa, pues también se habla con los ojos y con las manos; y demasiadas veces la locución suele ser vacío formalismo.

Precisamente porque el archigesto no tiene una función enunciativa, sino ética, tiene sentido la repetición. ¿A quién le extraña la repetición del

\footnotetext{
${ }^{23}$ Freud, S., El malestar de la cultura, Madrid, Alianza, 1979, pp. 7-11.
} 
“¿estás bien?"? La demanda de cuidado y de amparo siempre va a estar ahí. Por eso, la repetición de la acogida tiene mucho más sentido que la repetición de la enunciación. El archigesto es palabra de amparo actual, pero también de recuerdo y de promesa. Diacronía del amparo, al cual proporciona, en efecto, la dilatación temporal. Se puede hablar de los que ya no están entre nosotros, o puede hablarse del mañana que será. Palabra que intensifica los recursos del consuelo y que halla más medios para la calma y la confianza.

Incluso, a veces, cuando parece que el lenguaje sólo informa de los hechos, está haciendo algo distinto: alguien se dirige a otra persona para decirle algo que ha pasado o que ve y es como si se pusieran "los hechos" en la palma de la mano y levantándola levemente se convirtiese en ofrecimiento para el otro. Entonces, el dar cuenta se subordina a mi relación con el otro, a quien me dirijo solícitamente. Es decir, que también acogemos diciéndonos el mundo: "mira como amanece, mira el verde de los campos, mira los vagones del tren..."

Ya he cambiado el dictum de Heidegger (el lenguaje es la casa del ser) por la idea de que la palabra - del otro- es la casa del hombre y, por lo tanto, también del ser. Así, por ejemplo, en la novela The road, de C. McCarthy, se muestra sobre todo que en la devastación y la barbarie sólo queda el amor, y el cobijo del padre al hijo y del hijo al padre. Pero la dureza extrema de la "inclemencia" lleva precisamente a la plegaria, muralla y refugio. Se pide y se ruega porque se está en la precariedad. Se ruega, sobre todo, por los demás.

El hombre es ruego. Y no hace falta recurrir a personajes piadosos para ponerlo de relieve. Reveladoras son aquí las reflexiones de George Bataille cuando, sin concesiones, describe la experiencia interior: "Estado de desnudez, de súplica sin respuesta, en el que, sin embargo, advierto esto: que se aferra a la evitación de todo subterfugio. De tal suerte que, permaneciendo tales conocimientos particulares, menos el suelo, su fundamento, que les falta, me apercibo, al hundirme de que la única verdad del hombre, finalmente entrevista, es ser una súplica sin respuesta." ${ }^{24}$ Súplica sin respuesta. Y he aquí cómo alude Bataille a la función lenificante de las palabras: "Mis ojos se han abierto, es cierto, pero hubiera sido preciso no decirlo, permaneciendo fijo como un animal. He querido hablar, y como si las palabras llevasen el peso de mil sueños, suavemente, como fingiendo no ver, mis ojos se han cerrado." 25 Palabras tranquilizadoras, que adormecen como las nanas.

\footnotetext{
${ }^{24}$ Bataille, G., La experiencia interior, Madrid, Taurus, 1973, pp. 23-24.

${ }^{25}$ Ibid., p. 24.
} 
De acuerdo. Pero ¿cómo es que no hay nadie más? ¿Cómo es que, en estas páginas, Bataille no tiene en cuenta al prójimo, cuando la precariedad emerge sobre todo en el otro? ¿Dónde están la solicitud, el cuidado y el amor por el otro? La plegaria y la súplica están, como dice Saint-Exupéry, vinculadas al amor: "El amor es, en primer lugar, ejercicio de la plegaria y la plegaria ejercicio del silencio". El cuidado es sobre todo cuidado por el otro y la plegaria y la oración también. Como si la oración quisiera sostener y salvar al mundo; subiendo hacia arriba y convirtiendo el cielo, por lo menos provisionalmente, en cielo protector.

\section{Familiaridad y trascendencia}

Feuerbach, Marx, Nietzsche y Freud han insistido de diversos modos en el hecho de que la idea de Dios es una proyección no sólo realizada, obviamente, por nosotros sino de nosotros mismos. Feuerbach, a pesar de que empieza siendo hegeliano, procede posteriormente a la inversión que más tarde repetirá Marx. "La conciencia de Dios es la autoconciencia del hombre; el conocimiento de Dios el autoconocimiento del hombre" ${ }^{26}$. He aquí la reducción antropológica de la teología, que ha llegado hasta nuestros días con una incidencia enorme. Esta es la tesis de Feuerbach: "El hombre busca su esencia fuera de sí, antes de encontrarla en sí mismo". Dios — que, para Feuerbach, es evidentemente el Dios de los evangelios- sería una ilusión, un espejo en el cual el hombre se mira él mismo. Desde posiciones creyentes se ha querido a menudo rebatir esta tesis. Pero, ¿y si en lugar de rebatirla se radicalizara? Tal vez ocurriría entonces que el argumento de Feuerbach dejaría de lado las intenciones del propio autor con un salto inesperado. ¿Esta radicalización no coincidiría con lo que aquí hemos ensayado, con la idea del archigesto, esencia del habla? Eso sí: en lugar de "proyección” —al modo de Feuerbach - optaríamos más bien por usar la palabra "familiaridad" o "comunión" en lo esencial del habla, con lo que la connotación ya es diferente. Familiaridad que no excluye la trascendencia, sino que más bien la implica. Pensar la trascendencia es pensar la diferencia a partir de la esperanza en el mismo gesto. En una carta a Hugo Boxel, Spinoza escribía que, si un triangulo hablase, diría que Dios es triangular. Dos siglos y medio más tarde, Franz Rosenzweig le replicaba agudísimamente que "si el triángulo pudiese hablar, diría que Dios habla." ${ }^{27}$

\footnotetext{
${ }^{26}$ Feuerbach, L., Esencia del cristianismo, Madrid, Trotta, 1995, p. 65.

${ }^{27}$ Rosenzweig, F., Der Mensch und sein Werk. Gesammelte Schriften, Dordrecht, Martinus Nijhoff, 1976-1984, I, 1, p. 154.
} 
Y, con todo, quedaría todavía pendiente algo decisivo: ¿cómo hablaría Dios? Sin lugar a dudas, el mayor anhelo estaría en que lo hiciese según la esencia del habla humana; que hablase, no para discursear, ni para descubrir la verdad del mundo y sus leyes, sino más bien en el sentido del amparo, archigesto de la palabra humana.

Podemos imaginarnos nombrando todas las cosas del universo y teniendo teorías para todo, y experimentar, sin embargo, la misma pequeñez y el mismo desamparo: sólo apaciguados por la palabra amiga, que no exhibe la verdad de los hechos, sino que transmite el abrazo del alma. 